\title{
O reformismo educacional no contexto da mediação capital do trabalho: aproximações com as reformas curriculares em curso no Brasil
}

\author{
The educational reform in the context of the capital mediation of work: approximation \\ with the curricular reforms happening in Brazil
}

\author{
Flávia Moreira Ribeiro ${ }^{1}$ \\ Paulo Fioravante Giareta ${ }^{2}$
}

\begin{abstract}
Resumo
O presente trabalho tem por objeto a análise da mediação do capital sobre o trabalho e suas implicações para a educação, com especial incidência sobre a agenda de reformas curriculares. Responde pelo objetivo de aproximar teoricamente a caracterização das reformas curriculares em curso no Brasil às exigências dos modelos de organização do trabalho na sociedade capitalista. Metodologicamente, estrutura-se como análise dialética (FRIGOTTO, 1997). O trabalho possibilita perceber que as caracterizações e disciplinamentos exigidos pelo mundo capital ao trabalho implicam, consequentemente, em exigências reformistas para $o$ âmbito da educação, especialmente, para as políticas curriculares. Isto indica a contínua aplicação de um aparato reformista em educação, justificado como necessário para a adequação formativa do indivíduo, face às novas exigências do mundo do trabalho na sociedade capitalista.
\end{abstract}

Palavras-Chave: Trabalho. Educação. Reforma Curricular.

\begin{abstract}
The present work aims to analyze the role of the capital in the work market and its implications to education, especially concerning the curricular reform agenda. The present work has the objective of theoretically approaching the characteristics of curricular reforms in Brazil to the demands of a capitalist society and its organization. Methodologically, the work structures itself as a dialectic analysis (FRIGOTTO, 1997). The work makes it possible to realize that both the characterization and disciplining required by the capital world to face the work market consequently imply on reformist demands on the education field, especially on curricular policies. This indicates the continuous application of a reformist apparatus in the education, justified as necessary to the adequate formation of the individual, based on the demands of the work market in a capitalist society.
\end{abstract}

\footnotetext{
${ }^{1}$ Mestranda em Educação pelo Programa de Pós-Graduação em Educação da Universidade Federal do Mato Grosso do Sul - UFMS, Campus de Três Lagoas - CPTL (PPGEdu/CPTL). Membro do GForP - Grupo de Estudo e Pesquisa em Formação de Professores da Universidade Federal de Mato Grosso do Sul (UFMS), Campus de Três Lagoas (CPTL), Brasil. E-mail: flavinhamorei@gmail.com

${ }^{2}$ Doutor em Educação pela UFPR - Universidade Federal do Paraná. Professora da UFMS - Universidade Federal de Mato Grosso do Sul, CPTL - Campus de Três lagoas, Brasil. Professor do Programa de PósGraduação PPGEdu-CPTL. Líder do GForP - Grupo de Pesquisa em Formação de Professores. E-mail: pfgiareta27@yahoo.com.br
} 
Keywords: Work. Education. Curricular Reform.

\section{Introdução}

A expectativa social pela construção de uma sociedade democrática, pós Constituição de 1988, projeta a educação como lócus privilegiado, tanto para a apropriação dos conceitos caros à construção de uma consciência democrática, quanto para o exercício da socialização das relações de poder. Concepção que confere centralidade à política curricular assentada sobre a perspectiva crítica, contudo não deslocada das características do cenário político em disputa, especialmente pelo tensionamento para o reordenamento das matrizes de produção e acumulação, resultando em forte influência da mediação do capital sobre o trabalho, com incidência direta sobre a agenda de reformas para as políticas educacionais.

Esta agenda de reformismo curricular produziu, nas últimas décadas, ampla definição legal estruturada a partir de conceituações como currículo comum, parâmetros e/ou bases curriculares e diretrizes curriculares, assentada, atualmente, na denominada nova Base Nacional Comum Curricular (BNCC) que, sob a incidência dos agentes políticos de mercado, alinha a política curricular às novas demandas do trabalho, a partir da mediação do capital, conferindo centralidade às matrizes de competência e habilidades.

Macedo (2014), ao discutir as novas formas de sociabilidade produzidas a partir do processo de construção da Base Nacional Comum Curricular, destaca que a incidência consensuada ganha consistência prática pela atuação direta dos agentes de mercado. Este modelo de política curricular radicaliza a adoção das matrizes de competência e habilidades como matrizes estruturantes da própria organização da proposta curricular, espelhando o desenvolvimento de competências predefinidas, embasada em objetivos de aprendizagem, padrões de avaliação e o anunciado direito de aprendizagem, como referencial político norteador da proposta curricular, a qual foi objetivada pela BNCC no sistema educacional brasileiro.

Assim, este texto objetiva estabelecer aproximações teóricas entre as mudanças históricas do mundo do trabalho mediadas pelo capital e as possíveis implicações destas mudanças para a educação e o seu consequente disciplinamento a partir das políticas 
curriculares. $\mathrm{O}$ artigo está vinculado a um conjunto de pesquisas em desenvolvimento no GForP - Grupo de Estudo e Pesquisa em Formação de Professores, no âmbito da UFMS Universidade Federal de Mato Grosso do Sul, CPTL - Campus de Três Lagoas, Brasil, que tem como objetivo a elucidação dos fundamentos político-pedagógicos das reformas curriculares em curso no Brasil, especialmente as da reforma oficializada pela nova Base Nacional Comum Curricular.

Metodologicamente, o trabalho se estrutura a partir do método dialético, enquanto “exercício situado no plano da realidade, no plano da história, sob a forma da trama de relações contraditórias, conflitantes, de leis de construção, desenvolvimento e transformação dos fatos" (FRIGOTTO, 1997, p. 75), bem como possibilidade teórica e instrumento lógico de interpretação da realidade, sendo capaz de indicar um caminho epistemológico para o exercício de interpretação da proposta em análise (BENITE, 2009).

Assim, este trabalho se estrutura a partir da busca em demonstrar a caracterização histórica do trabalho, os processos de mediação do capital sobre o trabalho e a incidência deste modelo de apropriação das condições produtivas na educação.

\section{Considerações sobre o trabalho: aproximações necessárias}

A pesquisa parte do reconhecimento do trabalho como uma prática humana, portanto, inerente à busca humana pela sobrevivência, à satisfação de necessidades naturais e ao desenvolvimento. Enquanto o trabalho é considerado como atividade vital, que possibilita o desenvolvimento humano para convívio em evolução social e o desenvolvimento intelectual, criando um mundo de cultura humana.

[...] a ideia de origem animal do homem, mostrava ao mesmo tempo que o homem é profundamente distinto dos seus antepassados animais e que a hominização resultou da passagem, à uma vida em sociedade organizada pela base do trabalho; que esta passagem modificou a sua natureza e marcou o desenvolvimento dos animais, estava e está submetido não as leis biológicas, mas, as leis sócio-históricas. (LEONTIEV, 1978, p. 262). 
A evolução do homem, conforme indicada por Leontiev (1978), passa pela aquisição de habilidades e pela maturação racional, regidas sob as leis sócio-históricas. As transformações da natureza e a fabricação dos primeiros instrumentos ocorreram simultaneamente com as adaptações biológicas e, gradativamente, expressaram-nas em formas de cultura até o desenvolvimento intelectual/social mais elaborado do ser humano, como se apresenta na atualidade.

Para Hobsbawm (2015, p. 117), “o trabalho manual coletivo é, por tradição, uma atividade bastante ritualizada, profundamente entrelaçada com a estruturação ritual das vidas dos indivíduos e das coletividades sociais". Isto possibilita constarmos que ele caracteriza o ser humano pelo trabalho e vida em sociedade.

Segundo Antunes (2018, p. 112), “[...] é por meio dessa processualidade que o trabalho humano social se converte em elemento central do desenvolvimento da sociabilidade humana". Desse modo, o homem age pela busca de satisfação pessoal, alimentação, segurança, sobrevivência e conservação da espécie, transformando e sendo transformado na ação de fabricar e usar ferramentas, objetos facilitadores para provisão de sua subsistência, ao passo que evoluem.

Começaram produzir-se sob influência do desenvolvimento do trabalho e comunicação pela linguagem que ele se suscitava modificações da constituição anatômica do homem, do seu cérebro e órgãos dos sentidos, da sua mão e dos órgãos da linguagem; em resumo, o seu desenvolvimento biológico torna-se dependente do desenvolvimento de produção. (LEONTIEV, 1978, p. 262).

Ao longo da história, no princípio das atividades humanas, com o estabelecimento das relações dos indivíduos enquanto grupo, iniciou-se a construção de modos específicos de cultura e produção, de maneira, a obterem recursos, objetos com significados diversos. Logo, concebeu-se uma organização social hierárquica pautada não apenas na força e/ou instinto de sobrevivência, mas também em aspectos materiais de cada indivíduo, já expressos em pequenas relações de poder. 
Assim se desenvolvia o homem tornado sujeito do processo social de trabalho, sob ação de duas espécies de leis: em primeiro lugar as leis biológicas, em virtude que os órgãos se adaptaram às condições e às necessidades de produção, e as leis sócio-históricas que reagiam o desenvolvimento da própria produção e os fenômenos que a engendra. (LEONTIEV, 1978, p. 293).

Seguindo a análise de Leontiev (1978), é admissível afirmar que o desenvolvimento cultural e intelectual é marcado pela capacidade do homem de se adaptar e transformar a natureza, que se efetiva pela atividade do trabalho, sendo possível inferir, também, que as relações produtivas guiam os processos formativos, cuja ação, que em sua essência é intencional, materializa-se na atividade de superação, de mudanças de perspectivas e construção de culturas, configurando novas condições de vida (SAVIANI, 1984).

Assim, com base na ideia de desenvolvimento humano, é possível identificar o surgimento de ofícios demarcados por funções específicas na sociedade, como, por exemplo, o trabalho escravo e a servidão, cujos modelos se estruturam à sombra de imposição e castigo, sem quaisquer privilégios ao trabalhador (MARTINS, 2000), bem como a própria evolução do modelo capitalista, que, por sua vez, pressupõe a generalização da produção para a troca. Conforme destacado a seguir,

Com a expansão desta - entendida como expressão da diferenciação da divisão social do trabalho ocorre também a separação definitiva dos produtores diretos de mercadorias dos seus meios de produção. Expropriados, passam a ser possuidores de uma única mercadoria - sua força de trabalho. Proletarizados são convertidos em trabalhadores assalariados. Simples operadores dos instrumentos de produção que não mais lhes pertencem. (TEIXEIRA; SOUZA, 1985, p. 65).

A partir da prevalência do modelo capitalista, a força de trabalho passa a se referenciar pelo espectro avaliativo dos princípios do mercado. "O desenvolvimento do trabalho assalariado é, então, a própria fenomenologia da sua peculiaridade ontológica: ser "flexível" às necessidades imperativas do capital em processo.” (ALVES, 2011, p.14). 
Conforme já indicado, o homem é resultado do processo evolutivo e, em sua constituição, é um ser de natureza social, que se forma humano no seio da cultura criada pela humanidade, mediante práticas sociais, materiais e simbólicas, a priori dirigidas por motivações e necessidades sociais específicas de modo a atingir um objetivo. Portanto, todo aprendizado provém da experiência acumulada e assimilada no processo histórico social. "Por milhares de anos, os seres humanos se educaram de geração em geração aprendendo uns com os outros, dando respostas aos desafios e problemas no processo de produção de vida" (FRIGOTTO, 2013, p. 2).

Ao passo que as necessidades foram se complexificando, os conhecimentos populares não foram suficientes e deram espaço para novas formas instrumentais de conhecimento. As relações de aprendizagens, logo, passam da experiência da tradição à satisfação mercantil. Convém destacar que toda aquisição de saber é intencional, para tanto, a capacidade teleológica (de antever) é motivadora do percurso de concretização do objeto a ser internalizado em um processo contínuo de aprendizagem.

A qualificação humana diz respeito ao desenvolvimento das qualificações físicas, mentais, afetivas, estéticas e lúdicas do ser humano (condições omnilaterais) capazes de ampliar a capacidade de trabalho na produção dos valores de uso em geral como condição de satisfação das múltiplas necessidades do ser humano e seu devenir histórico (FRIGOTTO, 2010, p.34).

Deste modo, podemos assumir que as práticas educativas são subordinadas a determinantes complexos, que incluem as relações socioeconômicas explícitas ou não e estão indissociáveis a todo processo. Portanto, se o exercício produtivo passa a responder por uma mediação, agora capital, figura-se pertinente compreender como este modelo se reproduz socialmente, ou seja, como sua mediação alcança os processos formais de produção de cultura, aqui representada pelas políticas educativas em curso ou em disputa.

Nas palavras de Mészáros (2008, p. 45), essa reflexão implica em compreender os propósitos norteadores do processo educativo, já que indica estar diretamente subordinada aos desígnios políticos econômicos, respondendo como uma de suas funções é capaz de "produzir 
tanta conformidade "ou consenso" quanto for capaz, a partir e por meio dos seus próprios limites institucionalizados e legalmente sancionados".

\section{A mediação do capital nas relações de produção e a educação}

Por outro lado, a tradição marxista possibilita entender que as mutações no sistema capitalista figuram como movimentos necessários para a acomodação de suas contradições estruturais e, consequentemente, para sua afirmação como racionalização societal viável. É ilustrativo destas mutações do capital, enquanto uma condição para a sua reprodução, as mediações introduzidas na industrialização ocidental que emergiram no período pós-guerra de 1945.

Este modelo industrial reclama uma redefinição na apropriação dos meios de produção, que sociólogos do trabalho, como Antunes (2009, p. 23), denominaram de "sistema de metabolismo social". Em virtude disto, "com o capital erige-se uma estrutura de mando vertical, que instaurou uma divisão hierárquica do trabalho capaz de viabilizar o novo sistema de metabolismo social", subordinando, inclusive, as próprias práticas educativas.

Assim, a mediação capital do trabalho passa a demandar não só um aumento da oferta educacional, mas também uma oferta igualmente mediada pelo capital, centrada no processo de substituição progressiva do processo produtivo manual por meio do uso da maquinaria industrial. Segundo Alves (2011, p. 34), “a restruturação produtiva do capital no século XX foi marcada pelas inovações fordistas-tayloristas que alteraram a morfologia da produção de mercadorias em vários setores da indústria e dos serviços”.

Uma linha rígida de produção articulava diferentes trabalhos, tecendo vínculos entre ações individuais das quais a esteira fazia as interligações, dando ritmo e o tempo necessários para a realização de tarefas. Esse processo produtivo caracterizou-se, portanto, pela mescla da produção em série fordista com o cronometro taylorista, além da vigência de uma separação nítida entre elaboração e execução. Para o capital, tratava-se de apropriar-se do savoir-faire do trabalho "suprimido" a dimensão intelectual do trabalho operário, que era transferida para as esferas da gerência científica. A atividade do trabalho reduzia-se a uma ação mecânica e repetitiva (ANTUNES, 2009, p.39).

Revista Devir Educação, Lavras, vol.4, n.2, p.373-392 jul./dez., 2020. 
Dentre as interpretações de savoir-faire, apresenta-se a aquisição de competência, habilidade para resolução prática de trabalho específico, havendo a necessidade de vincular os esforços de instrução aos processos produtivos.

A primeira expressão modernizante da vinculação da instrução aos processos produtivos se estrutura a partir da proposta do engenheiro norte-americano Frederick Winslow Taylor, cuja metodologia estava pautada no progresso científico com a finalidade de extrair o "melhor" de cada operário nas suas produções em um aprimoramento hegemônico de intenção lucrativa.

Antunes (2009, p.39) lembra que esta proposta ganha espaço mediante a uma ampla estratégia propagandista de que "era necessário também racionalizar ao máximo as operações realizadas pelos trabalhadores, combatendo o 'desperdício' na produção, reduzindo o tempo e aumentando o ritmo de trabalho [...]", de maneira a valorar os rendimentos individuais. Até mesmo Taylor trabalhava com a ideia de que esta estratégia de administração cientifica tinha como justificativa ser "vantajosa" ao operário, pois o mesmo poderia aumentar seus rendimentos conforme empenho pessoal.

As transformações dos modos produtivos movimentaram a organização social globalmente. Esta racionalização científica do trabalho, centrada na dinâmica de maior produção com menor custo empregado, indicava efetiva reorganização capital dos meios de acumulação, mas também acompanhava a intensificação exaustiva das condições laborais dos trabalhadores.

O referido modelo de acumulação e produção parece representar mais que a divisão classista entre os detentores dos meios de produção e os operários que precisam vender sua força produtiva, contudo imperava a construção de um sistema que responsabilizasse o próprio trabalhador pela sua condição política e econômica no sistema produtivo.

Antunes e Pinto (2017, p. 31) chegam a indicar o próprio controle do trabalhador a partir de imposições, padronizações e empreendimentos pedagógicos como cerne da questão.

[...] pela qual caberia à gerência metamorfosear e impor, ao operariado, $\mathrm{o}$ conteúdo do seu próprio saber-fazer, anteriormente usurpado. Percebe-se, pois, que o controle dos corpos dos/as trabalhadores/as é apenas um 
corolário de todo um sistema, cujo cerne é uma apropriação do conhecimento, dos saberes-fazer que detém sobre o trabalho.

A mediação capital que pesa sobre todo o processo de produção e acumulação recai, também, sobre as práticas formativas escolares, que passam a responder pela função de assegurar qualidade técnica para os encargos fabris. $\mathrm{O}$ ordenamento produtivo capital que passa a mediar as relações de trabalho, consequentemente também as relações educativas, a partir da racionalidade científica, ganha consistência nas práticas industriais instituídas por Henry Ford, no ramo automobilístico, pela implementação da produção em escala.

O fordismo, agora denominado fordismo/taylorismo, enquanto modelo de produção em escala articulado para a produção e o consumo em massa, desencadeou um ritmo de forças produtivas que acelerou o crescimento do sistema capitalista e transformou o próprio modo da vida em sociedade. (ANTUNES, 2009).

À medida que ocorriam as alterações morfológicas das estruturas produtivas, os industriários se adequavam, não apenas em relação à maquinaria, mas também ao capital humano, de maneira a moldar os pressupostos curriculares educacionais, bem como ao oferecer cursos/formações essenciais aos funcionários de cada linha de produção. Este treinamento tinha o intuito de obter respostas rentáveis em larga escala, a partir de atribuições operacionais pontuais, dentro das fábricas.

Cada trabalhador era vinculado a uma função particular, a uma rotina homogênea padronizada, desqualificando-o para quaisquer outras funções dentro da empresa e resultando em novas relações de produção com forte impacto cultural, ao reordenar os modelos formativos com vista às afirmações e reprodução históricas. Proposição que foi assentada sob um modelo de formação técnica.

A relação manual/manufatureira de produção perde espaço e as pessoas precisam renovar seus conhecimentos para um processo técnico de trabalho, implicando na emergência de um modelo de educação mais utilitário, pragmático e fragmentado, chamado de pedagogia tecnicista. (SILVA, 2016).

Entre as décadas de 60 e 70, o modelo fordista/taylorista apresentou sinais de profunda crise, demandando novas formas de reorganização da mediação capital sobre a produção e os processos de acumulação. Esta metabolização do sistema capital passa a receber novos 
contornos pela aproximação com a experiência japonesa de produção, denominada de toyotismo.

Ao término da segunda guerra mundial, em resposta ao cenário de crise, a indústria japonesa inova em seu processo produtivo. A teoria toyotista agilizou não apenas o processo de produção, mas também de distribuição desta produção, que, nas explicações de Antunes e Pinto (2017), configurou-se em um trabalho não fragmentado, sem acúmulos de estoques, diferentemente das produções em séries estabelecidas nas fases anteriores.

Esse movimento oriental utilizou do progresso ligado às tecnologias informatizadas, radicalizando processos de controle e enxugando o número de trabalhadores com o aumento da maquinaria. Em resultado, uma proposta de organização produtiva atraiu a atenção do capitalismo ocidental, que já não encontrava mais condições de acumulação a partir do modelo taylorista/fordista.

O toyotismo figura como uma expressiva política de reorganização dos processos de produção e acumulação capitalista, assentado em amplo processo de flexibilização das relações de trabalho, terceirização das plantas produtivas, desburocratização administrativa e organização produtiva a partir do princípio do just-in-time, enquanto produção dos objetos em tempo certo e na quantidade demandada. Esse tipo de processo exigia do trabalhador o exercício produtivo a partir de múltiplas funções e do zelo pela qualidade, denominada como teoria/princípio da qualidade total.

Para Alves (2011, p. 51), “o Sistema Toyota de produção tem obsessão pela absoluta eliminação do desperdício". Partindo da afirmação de gestão de qualidade total, o sistema Toyota organizou um modelo flexível de produção, que teoriza a qualidade em todas as etapas produtivas e, em prática, busca atender prontamente as demandas mercadológicas, visando a precisão sem paralização de capital.

Em contrapartida os valores de uso das mercadorias produzidas sob essa gestão metodológica são estrategicamente reduzidos, ainda assim mantendo sempre a movimentação de mercado, seguindo uma lógica sustentada pela produção de somente o necessário, que utiliza menos homens e mais máquinas com uma grande rotatividade produtiva, uma vez que é consequência de uma obsolescência esperada.

[...] É um sistema que se estrutura no trabalho em equipe, rompendo com o caráter parcelar típico do fordismo, baseando-se num processo produtivo

Revista Devir Educação, Lavras, vol.4, n.2, p.373-392 jul./dez., 2020. 
flexível, onde o/a trabalhador/a opera simultaneamente várias máquinas. (ANTUNES; PINTO, 2017, p. 64).

Em tese: “quanto mais 'qualidade' as mercadorias aparentavam (e aqui a aparência faz a diferença), menor tempo de duração devem ter. Desperdício e destrutividade acabam sendo os seus traços dominantes" (ANTUNES, 2009, p. 53). Nessa perspectiva, o toyotismo instaurou suportes formativos com gerenciamentos humanos, intensificou a supervisão do não desperdício de matéria prima, tempo e força laborais, perante uma expressiva intenção monopolista de fiscalização e controle.

Contudo, o modelo toyotista, agora, também incorporado pelo capitalismo ocidental, não responde como modelo alternativo de apropriação do trabalho pelo capital, mas como reestruturação das relações de produção. A reestruturação promovida pelo capital, para além da ruptura da mudança, responde mais como reação necessária para reorganizar os padrões de acumulação. Este movimento reacionário do sistema de mediação do capital sobre o trabalho também se faz valer sobre as relações sociais, com especial incidência sobre a educação.

É demandado, também para a educação, um reordenamento, que, na prática, reforça a tese da concepção da educação como capital. Tese, agora, alinhada à racionalidade gerencial, aos métodos de gestão e aos domínios e controle tecnológicos em nome da qualidade nomeada Pedagogia da Qualidade Total.

A anunciada reorganização do sistema de ensino, em nome das novas formas de mediação do capital sobre o trabalho, confere centralidade ao gerencialismo e as ferramentas de gestão, sustentando a racionalização dos processos de trabalho a partir de uma volumosa inclusão de tecnologias e da consequente base produtiva mais flexível, o que demanda da educação um perfil curricular que privilegia a formação tecnológica, a inovação, o trabalho em equipe e o domínio de técnicas pedagógicas que otimizem o tempo e espaço formativos como treinamento para a qualidade.

Entretanto, a aderência do modelo toyotista na mediação capitalista de produção e na acumulação se apresenta limitado quanto à superação da crise estrutural do capitalismo, exigindo nova reestruturação. Esta nova proposta de reestruturação se assenta no aprofundamento radical dos princípios de flexibilização e precarização, princípios estes amplamente viabilizados pelo modelo toyotista, que, em termos teóricos e práticos, passam a denominar de modelo neoliberal. 
O neoliberalismo é viabilizado a partir da agenda de ajustes econômicos, foi formalizado em 1989, no âmbito do chamado Consenso de Washington, aportado na garantia do livre movimento do capital e das mercadorias à custa dos estados nacionais. A submissão dos estados, aqui, entende-se pela submissão de seus trabalhadores e o conjunto de suas políticas sociais, viabilizados por um amplo processo de reformas, capazes de orientar a estrutura estatal à serviço do novo arranjo capitalista de mediação dos processos de produção e acumulação.

Para Antunes (2009), a proposta de mediação produtiva neoliberal fortalece os processos de flexibilização e precarização total, em busca do avanço das políticas de seguridade social, de seguridade contratual, de terceirização irrestrita, de aprofundamento de ajustes e de regimes fiscais que penalizam o trabalho e o trabalhador.

Nesse processo agressivo sobre as bases produtivas e com potencial de vocacionar o estado à gestão da uberização, há a desregulamentação total das relações de trabalho, e portanto, das relações sociais.

Esta flexibilização total, enquanto nova agenda de reestruturação produtiva do modelo do trabalho, conferindo protagonismo marcante para a hegemonia financeira e a competitividade, naturaliza a crise estrutural expressa no déficit insuperável da empregabilidade e reordena a própria função dos processos educacionais, que devem voltar-se para a adaptação dos trabalhadores para novas competências, comportamentos adaptados ao mercado e para o empreendedorismo.

O neoliberalismo, assim, exige da escola e dos sistemas de ensino, tanto o aprofundamento da lógica da flexibilização assentada sobre matrizes tecnológicas para dar conta da nova organização estrutural do mundo do trabalho, quanto o aprofundamento lógico do controle gerencial em nome da aproximação adaptativa da educação às lógicas ilimitadas de precarização das relações de empregabilidade.

Esta dupla função exigida da escola viabiliza processos reformistas centrados no disciplinamento da política curricular, que, em países como o Brasil, encontra respaldo na implementação de nova Base Nacional Comum Curricular, a qual se baseia em matrizes de competência e habilidade, justificadas como proposta capaz de promover profunda revolução epistemológica na educação e, então, acabar conferindo centralidade a competências prédefinidas e alinhadas aos novos processos de mediação do capital sobre o trabalho. 


\section{O reformismo curricular como alinhamento da educação ao disciplinamento mediado pelo capital}

A pesquisa sobre os fundamentos político-pedagógicos das reformas curriculares em curso no Brasil, especialmente da BNCC - Base Nacional Comum Curricular, indica que a mediação do capital sobre as relações produtivas estrutura um amplo processo de adequação da educação. A necessária reestruturação dos meios de produção pela capital demanda e exige a própria readequação das condições sociais de produção.

O modelo fordista/taylorista, enquanto primeira forma de caracterização destas mediações do capital sobre as relações de produção e acumulação, pôs em curso uma proposta produtiva que acelerou o crescimento do sistema capital e transformou o próprio modelo de organização social (ANTUNES, 2009).

Esse modelo, por um lado, assentou os processos produtivos em ampla plataforma de racionalização científica e, por outro, apostou na especialização, na fragmentação e na tecnificação das relações de trabalho.

Processo produtivo que, para Antunes (2009, p. 39), caracterizou-se pela lógica da produção em série sobre a lógica do cronômetro. Acomodada à lógica da separação entre a elaboração e a execução, relativizava "a dimensão intelectual do trabalho operário, que era transferida para a esfera da gerência científica. A atividade de trabalho reduzia-se a uma ação mecânica e repetitiva".

O referido deslocamento busca viabilidade ideológica demandando, também, a reorganização cultural, o que impacta nos processos formativos e redefine as políticas curriculares no âmbito dos processos formais de escolarização. A submissão do trabalho à mediação do capital fomentou a ideia de que a própria educação se encerra no espectro do capital, proposta acomodada, a partir dos estudos de Schultz, na década de 60, na ideia de educação como capital - nomeada de Teoria do Capital Humano -, que possibilitou a organização de um modelo de educação mais utilitário, pragmático e fragmentado, chamado de Pedagogia Tecnicista (SILVA, 2016). 
No Campo da Educação, a teoria de capital humano gerou a concepção tecnicista sobre o ensino e sobre a organização da educação. Na concepção tecnicista, propagou-se a ideia de que a educação é o pressuposto do desenvolvimento econômico, chancelando a noção de que os investimentos em educação devem ser determinados pelos critérios do investimento capitalista (SILVA, 2016, 203).

A proposta da pedagogia tecnicista chega ao Brasil de forma articulada ao projeto de desenvolvimentismo econômico, no âmbito da política do estado militarizado e de seu ideário de modernização nacional aos moldes do desenvolvimento capitalista industrial. Proposição que orienta as políticas educacionais a partir da proposta da Teoria do Capital Humano e da leitura restritiva da educação como formação de recursos humanos para o desenvolvimento a partir dos parâmetros de ordem capital (SILVA, 2016).

A Reforma do Ensino Primário e Secundário, formalizada na Lei 5.692 de 1971, passa a ser representativa deste ideário curricular tecnicista, impondo a obrigatoriedade do ensino profissional para todos os jovens brasileiros e "a introdução de um currículo por áreas de estudo (não reconhecendo as disciplinas científicas) e com ênfase no desenvolvimento de habilidades, atitudes e conhecimentos necessários à integração no processo produtivo" (SILVA, 2016, p. 204).

O deslocamento do modelo fordista/taylorista de produção e tecnicista na educação, a partir da década de 1980, para o modelo flexível do toyotismo, enquanto reorganização dos instrumentos de mediação do capital sobre as condições concretas das relações produtivas, centrado no aparelhamento tecnológico e apegado aos métodos de gestão, produz novo reordenamento para a educação.

Este reordenamento se aporta à logica do gerencialismo, ferramenta de gestão empresarial do trabalho que afeta a educação, conferindo sustentação à racionalização dos processos de trabalho e alimentando o ideário de qualidade total e a inclusão massiva de tecnologia.

Antes de indicar uma ruptura com a mediação capital do trabalho e da educação, o referido reordenamento representa o aprofundamento dos pressupostos da Teoria do Capital Humano e confere nova roupagem à Pedagogia Tecnicista, agora traduzida por conceitos, como: Teoria das Competências, Sociedade do Conhecimento, Empregabilidade/Empreendedorismo, Qualidade Total, entre outros. 
Esta proposta responde por grande incidência no sistema educacional brasileiro, que, a partir da década de 1990, vê-se envolto a um conjunto de reformas, centradas no controle curricular pelo apego às políticas de avaliações centralizadas, externas à escola e de larga escala. Proposta que se estrutura a partir do ideário do controle e de fiscalização gerencial como princípio de modernização e qualidade educacional.

O próprio IPEA - Instituto de Pesquisa Econômica Aplicada -, fundação vinculada ao Ministério da Economia, Fazenda e Planejamento, em 1991, lançou um documento intitulado “Gestão da Qualidade Total nas Escolas: um novo modelo gerencial para a educação", propondo-se a trazer elementos para a mediação destas reformas.

$\mathrm{O}$ documento indica o modelo de qualidade objetivada pelo mercado como referência para a qualidade da educação. Parte da afirmativa que qualquer proposta com poder efetivo de qualificar a educação tem que se aportar no esforço de modernizar a gestão da educação e parametrizar sua estrutura curricular. Ideário que afeta, inclusive, a reforma curricular, que, na década de 1990, apresenta a política dos Parâmetros Curriculares Nacionais (PCN) como condição para adequação da educação nacional ao mundo do trabalho.

Vivemos numa era marcada pela competição e pela excelência, em que progressos científicos e avanços tecnológicos definem exigências novas para os jovens que ingressarão no mundo do trabalho. Tal demanda impõe uma revisão dos currículos, que orientam o trabalho cotidianamente realizado pelos professores e especialistas em educação do nosso país. (BRASIL, 1998, p. 5).

O reformismo curricular espelhado em propostas como da definição de parâmetros nacionais de currículo, tanto responde ao controle gerencial idealizado no âmbito do reordenamento das relações produtivas do modelo toyotista, quanto acena para processos de adequação neoliberal da relação trabalho e educação, que exigem o aprofundamento da lógica do gerencialismo sobre as políticas educacionais, em nome da aproximação adaptativa da educação aos processos de profunda precarização das relações de trabalho; e o aceno à lógica da flexibilização assentada sobre matrizes tecnológicas.

A própria política das Diretrizes Curriculares, a reboque das disputas entorno da implementação da política dos parâmetros curriculares, acaba por responder satisfatoriamente ao reposicionamento do sistema de ensino aos disciplinamentos e incidências das políticas 
curriculares internacionais mais centradas às exigências e ordenamentos econômicos do que a inclusão sociocultural e científica. "São processos que podem incluir desde a formulação de políticas curriculares mais amplas, até reconfigurações, redesenhos, adaptações ou adequações curriculares com foco nos conteúdos de conhecimento, nas aprendizagens dos estudantes, na avaliação e nas respectivas metodologias de ensino" (THIESEN, 2019, p.3).

O referido reposicionamento das políticas educativas e curriculares viabiliza o alinhamento da política educacional brasileira às demandas da atual ordem econômica, que encerram a política curricular ao ordenamento restritivo da expressão capitalista da relação entre trabalho e educação, apresentando a vinculada política curricular às matrizes de competência e de habilidades demandas pelo mercado de trabalho como referência para uma guinada epistemológica dos sistemas de ensino (CIAVATTA; RAMOS, 2012, p. 29).

Este modelo de política curricular radicaliza a adoção das matrizes de avaliação por competência e habilidades como matrizes estruturante da própria organização da matriz curricular, espelhando o desenvolvimento de competência predefinidas, assentadas sobre objetivos de aprendizagem, padrões de avaliação e o anunciado direito de aprendizagem, como referencial político epistemológico norteador da política curricular objetivada pela Base Nacional Comum Curricular (BNCC) no sistema educacional brasileiro.

Esta proposta resulta em novo aprofundamento das teses da Teoria do Capital Humano, ao rejuvenescer o tecnicismo pedagógico pela adoção da Pedagogia das Competências como fundantes das políticas de oferta e de avaliação dos projetos, e sistemas de educação.

Na BNCC, competência é definida como a mobilização de conhecimentos (conceitos e procedimentos), habilidades (práticas, cognitivas e socioemocionais), atitudes e valores para resolver demandas complexas da vida cotidiana, do pleno exercício da cidadania e do mundo do trabalho. (BRASIL, 2017, p. 8).

Contudo, a pedagogia das competências não aponta para uma mudança epistemológica da educação, mas para sua acomodação a partir de bases comportamentais. O termo competência parece estar ligado diretamente às políticas de gestão e ao cenário que envolve as relações de trabalho e formação. 
Convém destacar, em conformidade aos estudos de Ciervo e Silva (2019, p. 385), que o "neoliberalismo contemporâneo não é apenas um modo de regulação dos sistemas econômicos baseado na concorrência e no livre-mercado, como também um regime de gestão social e produção de formas de vida". Ou seja, parece possível falarmos, a partir da agenda neoliberal, no próprio sujeito como empresa - sujeito como empresa de si.

A referida mediação parece trazer as competências, comportamentos predefinidos eixo articulador da reforma curricular assentada na BNCC, como ativo capital. Proposta que reafirma o ideário proposto pela Teoria do Capital Humano, mas não mais como saber formal, da ordem técnica; como saber da experiência. Desse modo, "saber que exige que o indivíduo faça investimentos sobre si, sobre suas experiências, pois, na atualidade, o que é valorizado é o saber comportamental" (CIERVO; SILVA, 2019, p. 386).

Para Ramos (2001, p. 38), o referido deslocamento potencializa uma proposta de educação instrumentalizada para a racionalização dos novos arranjos da vida econômica e da produção, caracterizados pelas exigências de "flexibilização da produção e reestruturação das ocupações; integração de setores da produção; multifuncionalidade e polivalência dos trabalhadores; valorização dos saberes dos trabalhadores não ligados ao trabalho prescrito ou ao conhecimento formalizado".

Este deslocamento, na prática, caracteriza o esvaziamento da qualificação como relação social, agora, transmutada no conceito de competência, que "originário das ciências cognitivas, surge com uma marca fortemente psicológica para interrogar e ordenar práticas sociais" (RAMOS, 2001, p. 39).

Assim, a racionalidade (neo) tecnicista, quando afirmada a partir de competências prédefinidas, aprofunda a funcionalidade positivista do controle e da avaliação sobre a educação do trabalhador. Razão pela qual é possível indicar a reforma curricular objetivada pela BNCC como esforço de readequação da educação mediada pelo capital, no contexto do reordenamento dos instrumentos de produção e acumulação capital.

\section{Considerações finais}


A pesquisa indica que, não obstante, a reforma curricular oficializada pela BNNC promete uma revolução epistemológica no sistema educacional brasileiro, mas também em sua estruturação pelas matrizes de competências e habilidades, que guardam fidelidade às progressivas mutações dos instrumentos de produção e acumulação através da mediação capitalista.

O disciplinamento estrutural da BNCC, a partir de matrizes comportamentais competências predefinidas, está justificado como impeditivo para a promoção de novas bases político-epistemológicas e culturais. Diante da complexidade do mundo do trabalho e da vida em sociedade, contrariamente, parece indicar o esforço em vocacionar a educação para a adaptação dos processos sociais e culturais por meio da lógica restritiva de um trabalho mediado pelo capital e, consequentemente, da formação do trabalhador sob o espectro da mesma mediação.

Assim, as constantes e, supostamente, modernizantes agendas reformistas, na perspectiva da política curricular, respondem funcionalmente pelo rejuvenescimento das teses da teoria, a qual normatizou a compreensão da educação como capital. Isto é, a dada Teoria do Capital Humano também está assentada no princípio do tecnicismo pedagógico, que aproxima propostas como a BNCC a um suposto neotecnicismo pedagógico.

Essas constatações evidenciam a necessidade da continuidade de pesquisas que busquem elucidar os fundamentos político-pedagógicos das reformas curriculares em curso no Brasil, bem como sua caracterização como instrumento de disputa e de contradição, face à superação da mediação restritiva do capital.

\section{Referências}

ALVES, Giovani. Trabalho e subjetividade: O espírito do toyotismo na era do capitalismo manipulatório. São Paulo: Boitempo, 2011.

ANTUNES, Ricardo; PINTO, Geraldo Augusto: A fábrica da educação da especialização taylorista à flexibilização toyotista. São Paulo: Cortez, 2017.

ANTUNES, Ricardo. Os sentidos do trabalho: Ensaios sobre a afirmação e a negação do trabalho. 2 ed. São Paulo: Boitempo, 2009. 
ANTUNES, Ricardo. O privilégio da servidão: O novo proletariado na era digital. 1 ed. São Paulo: Boitempo, 2018.

BENITE, Anna Maria Canavarro. Considerações sobre o Enfoque Epistemológico do Materialismo Histórico-Dialético na Pesquisa Educacional. Revista Iberoamericana de Educación / Revista Ibero-america de Educação. n 50, 2009, p. 1 - 15.

BRASIL, Secretaria de Educação Fundamental. Parâmetros curriculares nacionais: terceiro e quarto ciclos do ensino fundamental: introdução aos parâmetros curriculares nacionais. Brasília: MEC/SEF, 1998.

BRASIL. Constituição de (1988). Constituição da República Federativa do Brasil. Brasília. Senado Federal, 1998.

BRASIL. Conselho Nacional de Educação. Resolução n 02 de 22 de dezembro de 2017. Base Nacional Comum Curricular. Brasília. 2017. Disponível: http://basenacionalcomum.mec.gov.br/images/historico/RESOLUCAOCNE CP222DEDEZE MBRODE2017.pdf Acesso em 25 de março de 2020.

BRASIL. Lei n. 5.692, de 11 de agosto de 1971. Lei de Diretrizes e Bases para o ensino de $1^{\circ}$ e $2^{\circ}$ graus, e dá outras providências. Diário Oficial [da] República Federativa do Brasil, Poder legislativo: Brasília, DF, 12.08.1971, Ano CLX, n. 203, Seção I, p. 6377-6380, 1971.

CIAVATTA, Maria; RAMOS, Marise. A "era das diretrizes": a disputa pelo projeto de educação dos mais pobres. Revista Brasileira de Educação. v. 17. n 49, jan/abr. 2012.

CIERVO, Tassia Joana Rodrigues; SILVA, Roberto Rafael dias da. A Centralidade das Competências Socioemocionais nas Políticas Curriculares Contemporâneas no Brasil. Revista e-Curriculum: São Paulo, v.17, n.2, p. 382 - 401, abr./jun. 2019.

FRIGOTTO, Gaudêncio. O Enfoque da Dialética Materialista Histórica na Pesquisa Educacional. In.: FAZENDA. Ivani. (Org). Metodologia da Pesquisa Educacional. São Paulo: Cortez, 1997, p. $69-90$.

FRIGOTTO, Gaudêncio. Educação e a crise do capitalismo real. São Paulo: 6 ed. Cortez, 2010.

FRIGOTTO, Gaudêncio. Novos fetiches mercantis da pseudo-teoria do capital humano no contexto do capitalismo tardio. Texto apresentado pelo autor na Aula Inaugural da rede municipal de ensino de Rio das Ostras, em 6 de fevereiro de 2013. Disponível em: http://www.sinproeste.org.br/wp-content/uploads/2013/04/O-rejuvenecimento-da-teoria-docapital-humano-no-contexto-do-capitalismo-tardio.pdf. Acesso em: 05 de maio de 2020.

HOBSBAWM. Eric J. Mundos do trabalho: Novos estudos sobre a história operária. São Paulo: 6 ed. Paz e Terra, 2015.

LEONTIEV, Alexis. O Desenvolvimento do Psiquismo: O Homem e a Cultura. Lisboa: Horizonte Universitário, 1978. 
MACEDO, Elizabeth. Base Nacional Comum Curricular: novas formas de sociabilidade produzindo sentidos para a educação. Revista e-Curriculum: São Paulo. V. 12, no 03, p. 1530 - 1555, out/dez. de 2014.

MARTINS, Sérgio Pinto. Breve histórico a respeito do trabalho. Universidade de São Paulo, 2000.

MÉSZÁROS, István. A educação para além do capital. São Paulo: Boitempo, 2008.

RAMOS, Marise Nogueira. A Pedagogia das Competências: Autonomia ou adaptação? São Paulo: Cortez, 2001.

SAVIANI. Demerval. Comunicação oral: Sobre a "Natureza e Especificidade da Educação", realizada pelo INEP, em Brasília, no dia 5 de julho de 1984.

SILVA, Andréa Villela Mafra da. A pedagogia tecnicista e a organização do sistema de ensino brasileiro. Revista HISTEDBR On-line. n 70: 2016, p. 197-209.

TEIXEIRA, Déa Lúcia Pimentel; SOUZA, Maria Carolina A. F. Organização do processo de trabalho na evolução do capitalismo. Rio de Janeiro: 1985.

THIESEN, Juares da Silva. Políticas Curriculares, Educação Básica Brasileira, Internacionalização: aproximações e convergências discursivas. Educação e Pesquisa: São Paulo, v. 45, 2019.

Recebido em 06/08/2020

Aprovado em 15/09/2020 